\title{
Exploring elite alleles for seed isoflavones concentration in soybean by association analysis
}

\author{
Cheng Wang, Yuan Guo, Jiafeng Hu, Jie Zhang, Liu Yang, Bei Guo, Jun Han, Hao Xie* \\ Beijing Key Laboratory of New Technology in Agricultural Application, College of Plant Science and Technology, Beijing University of \\ Agriculture, Beijing 102206, China
}

\section{A B S T R A C T}

\begin{abstract}
Soybean isoflavones are valuable in certain medicines, cosmetics, foods and feeds. Selection for high-isoflavone content in seeds along with agronomic traits is a goal of many soybean breeders. In our study, with 2 tables association mapping is a useful alternative to linkage mapping for the detection of marker-phenotype associations. Association analysis studies can be used to test for associations between molecular markers and target phenotype. The main objective of this study is to identify simple sequence repeat (SSR) markers associated with the soybean quality traits of isoflavones content. The four quality traits were evaluated in 135 soybean cultivar accessions from China, and the 135 accessions were genotyped with 100 SSR markers, analysis of population structure revealed three subgroups in the population. A total of 31 marker-trait associations related to the four traits were identified. According to the results, the association analysis in this study can be an effective method for QTL mapping and can help breeders to develop new approach for improving the content of isoflavones in soybean.
\end{abstract}

Keywords: Isoflavone content; Association analysis; Soybean; SSR; Genotype

\section{INTRODUCTION}

Soybean (Glycine max) has had a long history as a domesticated plant, originated from the eleventh century BC in China (Stephen Barnes 2010) and become a popular crop plant in China and East Asia, where they have long been cultivated as an important nutritional component of diets and used in many foods, such as soybean oil, soybean sprout, paste, soymilk and tofu (Kim EH et al. 2006). Nowadays, soybean is gaining acceptance in many countries largely as one of the best vegetable protein and oil sources, owing to its beans contains about $40 \%$ protein and $20 \%$ oil. By 2012 , annual world planting area had reached to 108.749 million hectares and production had risen to 267.999 million tons.

In recent decades, several studies have shown some components in soybean possess the health benefits. Regular consumption of soybean foods can reduce the incidence of breast, colon, and prostate cancers (Isanga J et al. 2008), prevent heart disease, osteoporosis (Messina M 2005) and lower plasma cholesterol (Hsu CS et al. 2001), and reduce menopausal symptoms (TY Tai et al. 2012). Isoflavone, a naturally occurring plant chemicals belonging to a category of polyphenols in soybean, were recognized most likely one of the components responsible for the health benefits of soybean and play a potential role in therapeutic or preventive effects on a range of hormone-dependent conditions (Messina M et al. 2006). These discoveries have resulted in the development and application of many functional foods and food supplements based on soybean isoflavones.

Isoflavones belong to a group of compounds that share a basic structure consisting of two benzyl rings joined by a three-carbon bridge. In soybean seed and soybean products, Isoflavones exist as aglycones (daidzein, genistein, and glycitein), 7-O- $\beta$-glucosides and two glucoside conjugate forms, acetylglucosides and malonylglucosides. Daidzein and genistein, the most abundant isoflavones found in soybeans, have chemical structures similar to estradiol (Knight DC and Eden JA 1996) and are both strong antioxidants and occupied $80 \%$ of antioxidant potential of soybean (Arora A et al. 2000; Hsu CS et al. 2001; Hwang J

\footnotetext{
*Corresponding author:

Hao Xie, Beijing Key Laboratory of New Technology in Agricultural Application, College of Plant Science and Technology, Beijing University of Agriculture, Beijing 102206, China. Fax: +861080799489, Tel: +861080799489, E-mail: xiehao@126.com 
et al. 2001). They have efficiently controlled or inhibited the growth of human breast cancer cell lines in culture (Lee HP 1991). These biological characters have resulted in attracting more attention to soybean seed isoflavones and an increasing interest in changes the isoflavones concentrations of soybean practical varieties.

Many of studies shown soybean seed isoflavones concentrations have a great fluctuations, because many biotic and abiotic factors influence their synthesis and accumulation. For example, the isoflavones could be determined over a wide concentration range (0.8$1135.0 \mathrm{mg} / \mathrm{kg}$ for daidzein, $1.9-1442.5 \mathrm{mg} / \mathrm{kg}$ for genistein and $0.5-54.6 \mathrm{mg} / \mathrm{kg}$ for glycitein) (Beatrix Preinerstorfer et al. 2004). Lucimara et al reported that isoflavones concentrations were influenced by the cytoplasm and the nuclear genes of the maternal parent (Lucimara Chiari et al 2006). Nevertheless, in spite of genetic factors, the environment interactions was largely influence on isoflavones concentration in seeds, such as soybean variety, cultivation year, cultivation location, and temperature (Hoeck JA et al. 2000; Lee SJ et al. 2002; Mebrahtu T et al. 2004; Murphy SE et al. 2009; Juan Jose et al. 2009). Juan et al found farther that isoflavones accumulation in seeds was influenced by multiple interacting genetic loci (Beatrix Preinerstorfer and Gerhard Sontag 2004), meanwhile, when plants grew in variable environments, epistasis has been considered as an important source of genetic variation.

Although seed isoflavones were attributable to genetic and environment causes as well as $g \times$ e interaction, the heritability of variety was still a key factor causing less phenotypic change in diverse environments. Hence, the main target of the present study was to investigate the variations in isoflavones concentrations in soybean seeds with cropping year. These informations may suggest ways to realize the heritability of isoflavones concentrations in soybean variety, which is very important for soybean breeders aiming to cultivate varieties with high isoflavones concentrations.

\section{MATERIALS AND METHODS}

\section{Plant materials}

A total of 135 soybean (Glycine max) varieties from different regions for this experiment were cultivated at same location during 2012-2014 in Beijing (Table S1). The soil was a silt clay loam year by year. The planting arrangement was $3 \times 1.5 \mathrm{~m}$ per plot, each plot consisted of three rows ( $3 \mathrm{~m}$ long and $0.5 \mathrm{~m}$ between rows) and the experiment completely randomized block design with three replicates. The fertilizers were applied prior to plowing at the recommended rates of $6.2,4.6$ and $5.0 \mathrm{~kg}$ per $666.67 \mathrm{~m}^{2}$
Table S1: Soybean varieties in our study

\begin{tabular}{|c|c|}
\hline \multicolumn{2}{|c|}{135 soybean varieties } \\
\hline $\mathrm{S1}$ & Zhonghuang4 \\
\hline $\mathrm{S} 2$ & Zhonghuang5 \\
\hline S3 & Zhonghuang7 \\
\hline S4 & Zhonghuang10 \\
\hline S5 & Zhonghuang18 \\
\hline S6 & Zhongpin94 \\
\hline S7 & Zhongpin6034 \\
\hline S8 & Zhongpin661 \\
\hline S9 & Zhongzuo96 \\
\hline S10 & Zhongzuo97 \\
\hline $\mathrm{S} 11$ & Zhongzuoyc17 \\
\hline S12 & Zhongzuo92 \\
\hline S13 & Zhongzuo98 \\
\hline $\mathrm{S} 14$ & Zhongzuo99 \\
\hline S15 & Jingfeng1 \\
\hline S16 & Ludou4 \\
\hline S17 & Ludou7 \\
\hline $\mathrm{S} 18$ & Ludou10 \\
\hline S19 & Yuejin4 \\
\hline S20 & Yuejin5 \\
\hline S21 & Hai94 \\
\hline S22 & JinDou1 \\
\hline S23 & Jindou3 \\
\hline S24 & Jindou19 \\
\hline S25 & Jindou20 \\
\hline S26 & Jindou24 \\
\hline S27 & Jindou25 \\
\hline S28 & Jindou27 \\
\hline S29 & Jindou47 \\
\hline S30 & Jinda74 \\
\hline S31 & Fendou53 \\
\hline S32 & Fendou57 \\
\hline S33 & Changzhi0201 \\
\hline S34 & Yudou6 \\
\hline S35 & Yudou8 \\
\hline S36 & Yudou10 \\
\hline S37 & Yudou16 \\
\hline S38 & Yudou18 \\
\hline S39 & Yudou19 \\
\hline S40 & Yudou21 \\
\hline S41 & Yaoheidou9011 \\
\hline S42 & Zhengdou6 \\
\hline S43 & Jichengdou1 \\
\hline S44 & Jidou7 \\
\hline S45 & Jidou12 \\
\hline S46 & Datuziyandou \\
\hline S47 & Bahong1 \\
\hline S48 & Dandou5 \\
\hline S49 & Dabaibian \\
\hline S50 & Xiaobaiqi \\
\hline S51 & Dabaiqi \\
\hline S52 & Dahuangke \\
\hline S53 & Tuzidun \\
\hline S54 & Tiefeng23 \\
\hline S55 & Tiefeng29 \\
\hline
\end{tabular}

Contd... 
Table S1: Soybean varieties in our study

\begin{tabular}{|c|c|}
\hline \multicolumn{2}{|c|}{135 soybean varieties } \\
\hline S56 & Kaiyu10 \\
\hline S57 & Xiaojianke \\
\hline S58 & Bu76 \\
\hline S59 & Andou3 \\
\hline S60 & Longjiang2 \\
\hline S61 & Suinong14 \\
\hline S62 & Huanandajinhuang \\
\hline S63 & Hongfeng10 \\
\hline S64 & Hefeng25 \\
\hline S65 & Longjianghuang \\
\hline S66 & longjianghei \\
\hline S67 & Dongbeihei \\
\hline S68 & Zhechundou2 \\
\hline S69 & Zhechundou3 \\
\hline S70 & Zhechundou13 \\
\hline S71 & Zhechundou14 \\
\hline S72 & Zhechundou18 \\
\hline S73 & Xudou3 \\
\hline S74 & Xudou5 \\
\hline S75 & Xudou7 \\
\hline S76 & Xudou8 \\
\hline S77 & Xudou9 \\
\hline S78 & Huaidou3 \\
\hline S79 & Xudou8901 \\
\hline S80 & Xinxuan2 \\
\hline S81 & Fengxianhonghuacao \\
\hline S82 & Aijiaozao \\
\hline S83 & Neimengdou1 \\
\hline S84 & Neimengdou2 \\
\hline S85 & Gansu3 \\
\hline S86 & Nannong94 \\
\hline S87 & Dagudi2 \\
\hline S88 & Bao9201 \\
\hline S89 & Qianjindou \\
\hline S90 & Xiafeng2 \\
\hline S91 & Zhengdou5 \\
\hline S92 & Hefeng35 \\
\hline S93 & Silihuang \\
\hline S94 & Jianheili \\
\hline S95 & Heidou1948 \\
\hline S96 & Kelong1 \\
\hline S97 & Kefeng2 \\
\hline S98 & Kefeng34 \\
\hline S99 & Dongbeidahongdou \\
\hline S100 & Kehuang1 \\
\hline S101 & Ji221 \\
\hline S102 & Daqingdou \\
\hline S103 & Zhonghuang1 \\
\hline S104 & Beinong103 \\
\hline S105 & Kefeng6 \\
\hline S106 & Kefeng14 \\
\hline S107 & Yi1358 \\
\hline S108 & Ludou9 \\
\hline S109 & Ludou11 \\
\hline S110 & Shandongsijiaodou \\
\hline
\end{tabular}

Contd...
Table S1: Soybean varieties in our study

\begin{tabular}{ll}
\hline & 135 soybean varieties \\
\hline $\mathrm{S} 111$ & Jindou11 \\
$\mathrm{S} 112$ & Jindou23 \\
$\mathrm{S} 113$ & Jinda841 \\
$\mathrm{S} 114$ & Jinda125 \\
$\mathrm{S} 115$ & Fendou41 \\
$\mathrm{S} 116$ & Taiguzao \\
$\mathrm{S} 117$ & Dandou4 \\
$\mathrm{S} 118$ & Dandou6 \\
$\mathrm{S} 119$ & Liufeng209 \\
$\mathrm{S} 120$ & Chidou \\
$\mathrm{S} 121$ & Jilin37 \\
$\mathrm{S} 122$ & Gongjiao5610 \\
$\mathrm{S} 123$ & Bawangbian \\
$\mathrm{S} 124$ & Suzao2 \\
$\mathrm{S} 125$ & Qingsu2 \\
$\mathrm{S} 126$ & Zhonglong1 \\
$\mathrm{S} 127$ & Tongsu823 \\
$\mathrm{S} 128$ & Nannong9610 \\
$\mathrm{S} 129$ & Chuxiu \\
$\mathrm{S} 130$ & Qingrenwudou \\
$\mathrm{S} 131$ & Fuxian1 \\
$\mathrm{S} 132$ & Zhe8018 \\
$\mathrm{S} 133$ & Taiwan292 \\
$\mathrm{S} 134$ & Tongsu1 \\
$\mathrm{S} 135$ & Qixing \\
\hline
\end{tabular}

for $\mathrm{N}, \mathrm{P}_{2} \mathrm{O}_{5}$ and $\mathrm{K}_{2} \mathrm{O}$, respectively. Soybean seeds were sowed on June 15-16 every year and harvested after mature completely for each variety from each replicate at each crop year and each plot were harvested only middle row as seed samples, and then stored at freezer with under $-18^{\circ} \mathrm{C}$ until analyzed for isoflavone concentration. Whole seed samples were analyzed the isoflavones and this analysis was undertaken at Beijing key laboratory of new technology in agricultural application, Beijing University of Agriculture.

\section{Isoflavone extraction and quantification}

Isoflavone concentrations were determined using HPLC as described by Vyn et al. (2002). Approximately $1 \mathrm{~g}$ sample was mixed with $5 \mathrm{ml}$ methanol $(100 \%)$ in $20 \mathrm{ml}$ plastic bottle and was used ultrasonic waves to make it dissolve quicker $1 \mathrm{~h}$, and then, static solution for $24 \mathrm{~h}$ at room temperature. $1.5 \mathrm{ml}$ methanol solution was extracted into centrifuge tube to separate $20 \mathrm{~min}$ at $14000 \mathrm{r} \cdot \mathrm{min}^{-1}$ using a refrigerated centrifuge. The supernatant liquor was filtered through a $0.45 \mu \mathrm{m}$ nylon syringe filter paper (Whatmanno42) to HPLC analysis.

The HPLC system consisted of an Agilent 1200 liquid chromatography pump and an detector (Agilent Technologies Co. 1td). The column for analysis was a TC-C18 (250 $\mathrm{mm} \times 4.6 \mathrm{~mm}, 5 \mu \mathrm{m})$, and UV absorption was measured at $254 \mathrm{~nm}$. The mobile phases consisted of solvents A and B in the HPLC analysis. Solvent A was 
$40 \%$ methanol and solvent B was $0.1 \%$ glacial acetic acid (pH3.22). The injection time was 20 min with $10 \mu l$ sample and solvent flow rate $1 \mathrm{ml} \cdot \mathrm{min}^{-1}$. The following gradient of mobile phase was used: $0-20 \mathrm{~min}$ isocratic at $40 \% \mathrm{~A}$ and $60 \% \mathrm{~B}, 20-25 \mathrm{~min}$ linear gradient from 40 to $100 \%$ $\mathrm{A}$ and from 60 to $0 \% \mathrm{~B}$, and then held during 25-40 min, 40-45 min linear gradient from 100 to $40 \% \mathrm{~A}$ and 0 to $60 \%$ B, 45-50minisocratic at $40 \% \mathrm{~A}$ and $60 \% \mathrm{~B}$. Identification and quantification of each isoflavone component were based on available standards (Indofine Chemical Co., Somerville, NJ). Measurements are given as micrograms of isoflavone per gram of seeds plus/minus standard deviation or standard error, when corresponds $(\mu \mathrm{g} / \mathrm{g} \pm$ SD or SE).

\section{SSR analyses}

Total DNA of each seed were isolated from freeze-dried leaf tissue by CTAB method (Doyle and Doyle 1990) (Doyle JJ et al. 1990). SSR analysis was performed with the primers developed by Cregan et al. (1999). PCR was performed in $20 \mu \mathrm{l}$ containing $2 \mu \mathrm{l}$ genomic DNA

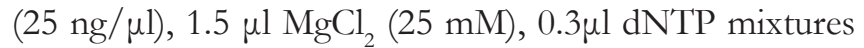
$(10 \mathrm{mM}), 2 \mu 110$ X PCR buffer, $2 \mu \mathrm{l} \mathrm{SSR} \mathrm{primer}(2 \mu \mathrm{M})$, $0.2 \mu \mathrm{l}$ Taq polymerase (10 units/ $\mu \mathrm{l}), 12 \mu \mathrm{l}$ double-distilled water. The amplification temperature profiles were $2 \mathrm{~min}$ at $94^{\circ} \mathrm{C}$, followed by 35 cycles of $30 \mathrm{~s}$ at $94^{\circ} \mathrm{C}, 30 \mathrm{~s}$ at $47^{\circ} \mathrm{C}$, $30 \mathrm{~s}$ at $72^{\circ} \mathrm{C}$, then $5 \mathrm{~min}$ at $72^{\circ} \mathrm{C}$. After amplification, the PCR products were mixed with loading buffer $(2.5 \mathrm{mg} / \mathrm{ml}$ bromophenol blue, $2.5 \mathrm{mg} / \mathrm{ml}$ diphenylamine blue, $10 \mathrm{mM}$ EDTA, 95\% (v/v) formamide), and denatured for $5 \mathrm{~min}$ at $94^{\circ} \mathrm{C}$ and then kept on ice for $5 \mathrm{~min}$. The denatured PCR products were separated on $6 \%(\mathrm{w} / \mathrm{v})$ denaturing polyacrylamide gel and visualized by silver straining (Trigizano RN et al. 1998).

\section{Population structure}

Population structure was estimated by STRUCTURE v2.3.2 (Pritchard et al. 2000) (Pritchard JK et al. 2000). The number of hypothetical subpopulations $(\mathrm{K})$ was set from 2 to 9 with a burn-in period length of 50,000 iterations and a run of 500,000 replications of Markov Chain Monte Carlo (MCMC) after burn-in. Each K was duplicated five times. The admixture model of STRUCTURE allowed for population mixture and correlated allele frequencies. The most appropriate $\mathrm{K}$ value was evaluated by $\ln \mathrm{P}(\mathrm{D})$ in the STRUCTURE output (Evanno et al. 2005). According to the most appropriate $\mathrm{K}$ value, the Q-matrix of five repeats was integrated by using the CLUMPP software (Jakobsson and Rosenberg 2007).

\section{Association mapping}

For marker-trait association, a structured association approach was implemented by a general linear model (GLM) in TASSEL 2.1 (Bradbury PJ et al. 2007). In order to correct for spurious associations, the Q-matrix was used in the model. The threshold (P value) for significant association between markers and traits was 0.001 . The phenotypic variance explained (PVE) for each significantly associated locus was evaluated by $\mathrm{R}^{2}$ values for the markers (Zhang J et al. 2011).

\section{Statistical analysis}

The soybeans were cultivated using a completely randomized design, which was replicated three times. The analysis of isoflavones by HPLC was repeated three times with each variety. Analyses of variance for all data were undertaken using the general linear model procedure and the SPASS17.0 software. The pooled mean values were separated on the basis of least significant differences at the 0.05 probability level.

\section{RESULTS}

\section{Phenotypic analysis of isoflavone content}

According to the result of isoflavone content, the mean content of total isoflavone (TI) in different soybean varieties was $1579.14 \mu \mathrm{g} / \mathrm{g}$, ranging from 479.32 to $2721.44 \mu \mathrm{g} / \mathrm{g}$, with a coefficient of variation(CV) of $38.66 \%$. The mean content of daidzein(DZ) in different soybean varieties was $587.15 \mu \mathrm{g} / \mathrm{g}$, ranging from 219.67 to $1346.96 \mu \mathrm{g} / \mathrm{g}$, with a coefficient of variation(CV) of $45.11 \%$. The mean content of genistein(GT) in different soybean varieties was $801.72 \mu \mathrm{g} / \mathrm{g}$, ranging from 224.11 to $1620.08 \mu \mathrm{g} / \mathrm{g}$, with a coefficient of variation(CV) of $41.84 \%$, The mean content of glycitein (GC) in different soybean varieties was $190.27 \mu \mathrm{g} / \mathrm{g}$, ranging from 3.87 to $122.45 \mu \mathrm{g} / \mathrm{g}$, with a coefficient of variation(CV) of $15.9 \%$ (Table 1). The high values of $\mathrm{CV}$ indicated wide phenotypic variation among accessions, which was suitable for association analysis.

\section{Allelic diversity and population structure}

A total of 100 SSR markers were used to detect polymorphisms in all soybean varieties. A key issue for association analysis is estimation of population structure, which can result in spurious associations between phenotypes and markers. The Q-matrix from STRUCTURE can help to reduce the risk of false positives arising from population structure (Bradburyet al. 2007). One hundred SSR markers were selected to estimate the population structure. The average $\ln \mathrm{P}(\mathrm{D})$ value for each $\mathrm{K}$ (from 1 to 8 ) is visualized in Fig S1 and the inflection point appeared at $\mathrm{K}=3$. According to $\ln \mathrm{P}(\mathrm{D})$, Population was classified into three subpopulations, containing 65,16 and 66 accessions, respectively (Fig. S2).

\section{Content of isoflavone by association analysis}

Candidate SSR markers for content of isoflavone, located indifferent regions, were used for association analysis in 
Table 1: Conditional phenotypic values for isoflavone

\begin{tabular}{lcccc}
\hline Content & Mean \pm SD $(\mu \mathrm{g} / \mathrm{g})$ & $\mathrm{CV}(\%)$ & Min. $(\mu \mathrm{g} / \mathrm{g})$ & Max. $(\mu \mathrm{g} / \mathrm{g})$ \\
\hline Daidzein & $587.15 \pm 29.36$ & 45.1 & 219.7 & 1347.0 \\
Genistein & $801.72 \pm 40.09$ & 41.8 & 224.1 & 1620.1 \\
Glycitein & $190.27 \pm 9.51$ & 15.9 & 3.87 & 122.45 \\
Isoflavone & $1579.14 \pm 78.96$ & 38.7 & 479.3 & 2721.4 \\
\hline
\end{tabular}

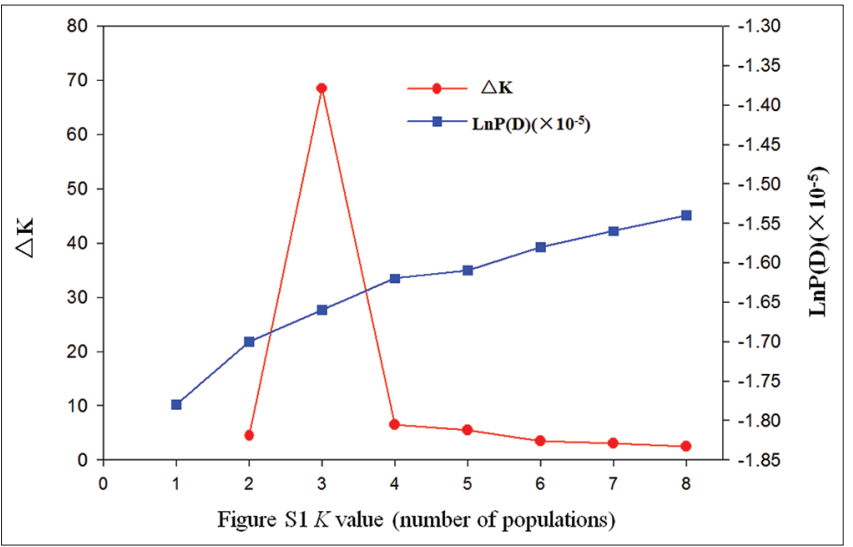

Fig S1. Values of $\Delta \mathrm{K}$ with its modal value used to detect the true $\mathrm{K}$ of three subgroups $(K=3)$.

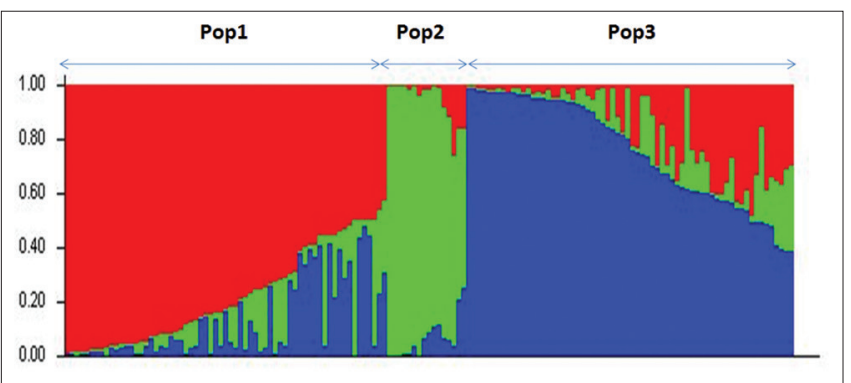

Fig S2. Population was classified into three subpopulations.

population. One hundred SSR markers which distributed in every chromosome were selected to estimate the association analysis for daidzein, genistein, glycitein and total content of isoflavone. We selected the models about GLM, found too many loci association with the correlative traits. Under the GLM model, twelve loci (Satt440、Satt592、Satt155、 Satt376, Satt186, Satt384, Satt038, Satt621, Satt375, Satt 540, Satt241, Sat_120) significantly associated with DZ, located in I, O, A1, C2, D2, E, G, J, K, M, O and F, respectively. Of them, phenotypic variation explained is about 5\% to 13\% (Table 2). Fourteen loci (Satt687, Sat_337, Satt009, Satt629, Satt431, Satt187, Satt038, Satt288, Satt54 6, Satt621, Satt264, Sat_096, Satt 002, Satt114) significantly associated with GC, located in B2, C1, H, H, J, A2, G, G, D1b, J, K, D1b, D2 and F, respectively. Of thm, phenotypic variation explained is about 6\% to $34 \%$ (Table 2). Twelve loci (Satt129, Sat_592, Satt376, Satt540, Satt546, Satt587, Satt375, Satt245, Satt323, Satt080, Satt516, Satt543) significantly associated with GT, located in D1a, O, C2, M, D1b, I, K, M, M, N, D1a and $\mathrm{D} 2$, respectively. Of them, phenotypic variation
Table 2: The list of marker analysis for associated with isoflavone under GLM model

\begin{tabular}{|c|c|c|c|c|c|}
\hline Traits & Primer & $P$ value & $\mathbf{R}^{2}(\%)$ & Linkage group & Locus \\
\hline \multirow[t]{12}{*}{$\overline{\mathrm{DZ}}$} & Satt440 & 0.00026 & 5.0 & I & 112.7 \\
\hline & Satt592 & 0.00034 & 10.3 & $\mathrm{O}$ & 100.38 \\
\hline & Satt155 & 0.00030 & 13.4 & $\mathrm{~A} 1$ & 32.68 \\
\hline & Satt376 & 0.00025 & 9.8 & $\mathrm{C} 2$ & 97.83 \\
\hline & Satt186 & 0.00027 & 4.9 & D2 & 105.45 \\
\hline & Satt384 & 0.00036 & 5.8 & $E$ & 19.3 \\
\hline & Satt038 & 0.00048 & 5.4 & $\mathrm{G}$ & 1.84 \\
\hline & Satt621 & 0.00032 & 6.0 & $\mathrm{~J}$ & 53.68 \\
\hline & Satt375 & 0.00020 & 6.7 & $\mathrm{~K}$ & 45.81 \\
\hline & Satt540 & 0.00013 & 8.6 & $M$ & 53.54 \\
\hline & Satt241 & 0.00015 & 7.1 & O & 59.49 \\
\hline & Sat_120 & 0.00045 & 10.7 & $\mathrm{~F}$ & 75.97 \\
\hline \multirow[t]{14}{*}{ GC } & Satt687 & 0.00001 & 18.5 & B2 & 113.61 \\
\hline & Sat_337 & 0.00019 & 6.7 & $\mathrm{C} 1$ & 32.1 \\
\hline & Sctt009 & 0.00023 & 7.6 & $\mathrm{H}$ & 38.89 \\
\hline & Satt629 & 0.00010 & 33.6 & $\mathrm{H}$ & 72.18 \\
\hline & Satt431 & 0.00010 & 10.5 & $\mathrm{~J}$ & 78.57 \\
\hline & Satt187 & 0.00025 & 6.3 & A2 & 54.92 \\
\hline & Satt038 & 0.00023 & 6.5 & $\mathrm{G}$ & 1.84 \\
\hline & Satt288 & 0.00035 & 10.1 & $\mathrm{G}$ & 76.77 \\
\hline & Satt546 & 0.00027 & 7.4 & D1b & 99.5 \\
\hline & Satt621 & 0.00310 & 6.0 & $\mathrm{~J}$ & 53.68 \\
\hline & Satt264 & 0.00010 & 17.3 & $\mathrm{~K}$ & 46.25 \\
\hline & Sat_096 & 0.00015 & 7.1 & D1b & 0 \\
\hline & Satt002 & 0.00010 & 18.3 & D2 & 47.73 \\
\hline & Satt114 & 0.00024 & 10.8 & $\mathrm{~F}$ & 63.69 \\
\hline \multirow[t]{12}{*}{ GT } & Satt129 & 0.00036 & 12.9 & $\mathrm{D} 1 \mathrm{a}$ & 109.67 \\
\hline & Satt592 & 0.00027 & 9.9 & 0 & 100.38 \\
\hline & Satt376 & 0.00049 & 8.0 & $\mathrm{C} 2$ & 97.83 \\
\hline & Satt540 & 0.00032 & 9.6 & M & 53.54 \\
\hline & Satt546 & 0.00026 & 6.9 & D1b & 99.5 \\
\hline & Satt587 & 0.00016 & 8.7 & 1 & 31.49 \\
\hline & Satt375 & 0.00011 & 7.0 & $\mathrm{~K}$ & 45.81 \\
\hline & Satt245 & 0.00025 & 7.0 & $M$ & 53.54 \\
\hline & Satt323 & 0.00049 & 6.0 & M & 60.05 \\
\hline & Satt080 & 0.00020 & 16.2 & $\mathrm{~N}$ & 45.14 \\
\hline & Satt516 & 0.00045 & 7.1 & D1a & 55.68 \\
\hline & Satt543 & 0.00036 & 4.2 & D2 & 88.02 \\
\hline \multirow[t]{8}{*}{ TI } & Satt592 & 0.00023 & 10.6 & $\mathrm{O}$ & 100.38 \\
\hline & Satt376 & 0.00015 & 10.3 & $\mathrm{C} 2$ & 97.83 \\
\hline & Satt546 & 0.00037 & 9.8 & D1b & 87.2 \\
\hline & Sat_218 & 0.00026 & 7.2 & $\mathrm{H}$ & 99.5 \\
\hline & Satt587 & 0.00020 & 8.8 & 1 & 31.49 \\
\hline & Satt375 & 0.00040 & 8.6 & $\mathrm{~K}$ & 45.81 \\
\hline & Satt540 & 0.00030 & 9.4 & M & 53.54 \\
\hline & Satt543 & 0.00045 & 4.1 & $\mathrm{D} 2$ & 88.02 \\
\hline
\end{tabular}

$\mathrm{R}^{2}$ Indicates the degree of the locus of the phenotypic variance explained at $\mathrm{P}<0.05$ level

explained is about $4.2 \%$ to $12.9 \%$ (Table 2). eight loci (Satt592、Satt376, Satt546, Sat_218, Satt587, Satt375, Satt540, Satt543)significantly associated with TI, located in $\mathrm{O}, \mathrm{C} 2, \mathrm{D} 1 \mathrm{~b}, \mathrm{H}, \mathrm{I}, \mathrm{K}, \mathrm{M}$, and $\mathrm{D} 2$, respectively. Of them, phenotypic variation explained is about $4.1 \%$ to 10.6\% (Table 2). 


\section{DISCUSSION}

Soybean seed isoflavones have many uses in foods, medicines, cosmetics, and animal farming (Brouns F 2002). Thus, the improvement of seed isoflavone content in soybean cultivar is increasingly focused by breeders. Fendou53 $(2721.44 \mu \mathrm{g} / \mathrm{g})$ was proved to have highest isoflavone content in all soybean varieties for three years. Choi et al. (1996) showed their results that total isoflavone content changed from 458 to $3309 \mu \mathrm{g} / \mathrm{g}$ across location within the same year to single or multiple soybean cultivars (Wang H and Murphy P 1994; Choi JS et al. 1996). In our study. The TI values see table 1 (Table 1). Meanwhile, seed isoflavones were attributable to genetic and environment causes as well as $\mathrm{g} \times \mathrm{e}$ interaction or year $\times$ location, these studies showed that for effective cultivar improvement, the main genotypic effects of total and individual isoflavone have the important influence.

The 100 SSR markers selected for association analysis, twelve loci associated with DZ, fourteen loci associated with DC, twelve loci associated with GT, and eight loci associated with TI were mapped onto eleven, eleven, ten and eight LGs, respectively. There association loci explained $4.1-10.6 \%$ of phenotypic variation for total isoflavone. Most of variation was $<30 \%$. In soybean seeds, the low level of phenotypic variation evaluated by association analysis was similar to the other studies (Njiti VK 1999; Meksem K et al. 2001; Kassem MA et al. 2004; Kassem MA et al. 2006; Primomo VS et al. 2005).

In this study, thirty-one SSR markers associated with DZ、GC、GT and TI, and in these markers, same marker (satt540 in LG M) had been detected in DZ、GT and TI at the same time. Wang yan et al. (2014) used 'Zhongdou27' (high isoflavone) $\times$ 'Jiunong20' (low isoflavone) to dentify eQTL underlying expression of four gene families encoding isoflavone synthetic enzymes involved in the phenylpropanoid pathway including the Satt540 marker. Primomo et al. (2005) detected Satt540 marker was from different isoflavone content in soybean seeds (Primomo VS et al. 2005). Zeng Guoliang et al (2009) also detected Satt540 marker was associated with GC、GT and TI. In our study, same marker (satt540 in LG M) had been detected in DZ、GT and TI. This suggests Satt540 was weakly influenced by genetic background and environment. Meanwhile, Satt540 was associated with certain foliar resistances such as to aphids and to white mold ( $\mathrm{Li} \mathrm{Y}$ et al. 2007; Guo XM et al. 2008). Furthermore, isoflavones in leaves that protectd soybeans from pests or pathogenic microbes may be transported to seed (Morris PF et al. 1991; Benhamou N et al. 1999). Therefore, Satt540 marker in this region could represent a major seed isoflavone content locus. SSR marker (Satt546 in LG D1b) was associated with
GC、GT and TI, it was a creativity discover related to seed isoflavone content, in this region of soybean genome, a QTL for expression of gene family encoding isoflavone synthetic enzymes: $\mathrm{CHH}$ (cinnamate-4-hydroxylase) (Yan Wang et al. 2014).

The present study investigated a number of SSR marker associated with DZ、GC、GT and TI, and predicted some SSR markers related to the isoflavone contents in soybean seeds.

Although seed isoflavonoids display a broad range of variation, their synthesis and accumulation are affected by many biotic and abiotic factors. There are considerableadvances in these studies. In our study, the usability of these markers associated with isoflavones in soybean seeds could promote MAS in breeding programs, and improve an efficient method for developing soybean cultivars.

\section{CONCLUSION}

In summary, our findings suggested that 31 marker-trait associations related to the four traits were identified, including the SSR markers (Satt540 and Satt546) which have been previously reported. The results also suggested that the use of the SSR marker (Satt540 and Satt546) could probably improve an efficient method for developing highisoflavone soybean cultivars.

\section{ACKNOWLEDGEMENTS}

This work was supported by the Beijing Natural Science Foundation (5122009); The National Natural Science Fund (31371648) and the "863" State High Tech Programs (2012AA101106).

\section{Author contribution}

Study Concepts: Cheng Wang, H. X.; Study Design: C. W.; Material Preparation: Y.G., J.F.H.; Literature Research: C. W., B. G.; Data analysis/Interpretation: C. W.; Statistical analysis: C. W., H. X., L. Y.; Manuscript Preparation: C. W., J. Z.; Manuscript definition of intellectual content: C. W.; Manuscript editing: C. W.; Manuscript Revision/Review: C. W., J. H.; Manuscript Final Version Approval: C. W.All authors read and approved the manuscript.

\section{REFERENCES}

Arora, A., S. Valcic, S. Cornejo, M. G. Nair, B. N. Timmermann and D. C. Liebler. 2000. Reactions of Genistein with alkylperoxyl radicals. Chem. Res. Toxicol. 13(7): 638-645. 
Preinerstorfer, B. and G. Sontag. 2004. Determination of isoflavones in commercial soy products by HPLC and coulometric electrode array detection. Eur. Food Res. Technol. 219: 305-310.

Benhamou, N. and M. Nicole. 1999. Cell biology of plant immunization against microbial infection: The potential of induced resistance in controlling plant diseases. Plant Physiol. Biochem. 37(10): 703-719.

Bradbury, P. J., Z. W. Zhang, D. E. Kroon, T. M. Casstevens, Y. Ramdoss and E. S. Buckler. 2007. TASSEL: Software for association mapping of complex traits in diverse samples. Bioinformatics. 23: 2633-2635.

Brouns, F. 2002. Soya isoflavones: A new and promising ingredient for the health food sector. Food Res. Int. 35(2-3): 187-193.

Choi, J. S., T. W. Kwon and J. S. Kim. 1996. Isoflavone contents in some varieties of soybean. Korean Food Biotechnol. 5: 167-169.

Cregan, P. B., T. Jarvik, A. L. Bush, R. C. Shoemaker, K. G. Lark, A. L. Kahler, T. T. Van Toai, D. G. Lohnes, J. Chung and J. E. Specht. 1999. An integrated genetic linkage map of the soybean genome. Crop Sci. 39: 1464-1490.

Doyle, J. J. and J. L. Doyle. 1990. Isolation of plant DNA from fresh tissue. Focus. 12: 13-15.

Evanno, G., S. Regnaut and J. Goudet. 2005. Detecting the number of clusters of individuals using the software structure: Asimulation study. Ecol. Entomol. 14: 2611-2620.

Zeng, G., D. Li, Y. Han, W. Teng, J. Wang, L. Qiu and W. Li. 2009. Identification of QTL underlying isoflavone contents in soybean seeds among multiple environments. Theor. Appl. Genet. 118: 1455-1463.

Guo, X. M., D. H. Wang, S. G. Gordon, E. Helliwell, T. Smith, S. A. Berry, S. K. St Martin and A. E. Dorrance. 2008. Genetic mapping of QTLs underlying partial resistance to Sclerotinia sclerotiorum in soybean PI 391589A and PI 391589B. Crop Sci. 48: 1129-1139.

Hsu, C. S., W. W. Shen and Y. M. Hsueh. 2001. Soybean isoflavones supplementation in postmenopausal women. Effects on plasma lipids, antioxidant enzyme activities and bone density. J. Reprod. Med. 46(3): 221-226.

Hwang, J., H. N. Hodis and A. Sevanian. 2001. Soy and alfalfa phytoestrogen extracts become potent low-density lipoprotein antioxidants in the presence of acerola cherry extract. J. Agric. Food Chem. 49(1): 308-314.

Hoeck, J. A., W. R. Fehr, P. A. Murphy, and G. A. Welke. 2000. Influence of genotype andenvironment on isoflavones concentrations of soybean. Crop Sci. 40: 48-51.

Jakobsson, M. and N. A. Rosenberg. 2007. CLUMPP: A cluster matching and permutation program for dealing with labels witching and multimodality in analysis of population structure. Bioinformatics. 23: 1801-1806.

Isanga, J. and G. N. Zhang. 2008. Soybean bioactive components and their implications to health - A review. Food Rev. Int. 24: 252-276.

Gutierrez-Gonzalez, J. J., X. Wu, J. Zhang, J. D. Lee, M. Ellersieck, J. G. Shannon and O. Yu. 2009. Genetic control of soybean seed isoflavones concentration: Importance of statistical model and epistasis in complex traits. Theor. Appl. Genet. 119: 1069-1083.

Kassem, M. A., K. Meksem, V. Njiti, W. J. Banz, T. A. Winters and A. J. Wood. 2004. Definition of soybean genomic regions that control seed phytoestrogen amounts. J. Biomed. Biotechnol. 2: 52-60.

Kassem, M. A., J. Shultz, K. Meksem, Y. Cho and A. J. Wood. 2006. An updated 'Essex' by 'Forrest' linkage map and first composite interval map of QTL underlying six soybean traits. Theor. Appl. Genet. 113: 1015-1026.

Kim, E. H., J. I. Chung, H. Y. Chi, J. A. Kim and I. M. Chung. 2006. Analysis of phenolic compounds and isoflavones in soybean seeds (Glycine max (L.) Merill) and sprouts grown under different conditions. Eur. Food Res. Technol. 222: 201-208.

Knight, D. C. and J. A. Eden. 1996. A review of the clinical effects of phytoestrogens. Obstet. Gynecol. 87: 897-904.

Lee, H. P., L. Gourley, S. W. Duffy, J. Esteve and N. E. Day. 1991. Dietary effects on breast cancer in Singapore. Lancet. 537: 1197-1200.

Lee, S. J., W. Yan and A. Chung. 2002. Effects of year, site, genotype and their interactions on various soybean isoflavones. Field Crops Res. 4150: 1-12.

Li, Y., C. B. Hill, S. R. Carlson, B. W. Diers and G. L. Hartman. 2007. Soybean aphid resistance genes in the soybean cultivars Dowling and Jackson map to linkage group M. Mol. Breeding. 19: $25-34$

Lucimara, C., L. K. Naoel and N. D. Piovesan. 2006. Inheritance of isoflavones concentrations in soybean seeds. Euphytica. 150: 141-147.

Mebrahtu, T., A. Mohamed, C. Y. Wang and T. Andebrhan. 2004. Analysis of isoflavones concentrations in vegetable soybeans. Plant Foods Hum. Nutr. 59: 55-61.

Meksem, K., V. Njiti, W. J. Banz, M. M. Kassem, D. Hyten, J. Yuang and T. A. Winters. 2001. Molecular markers of phytoestrogen content in soybeans. J. Biomed. Biotechnol. 1: 38-44.

Messina, M., O. Kucuk and J. W. Lampe. 2006. An overview of the health effects of isoflavones with an emphasis on prostate cancer risk and prostate-specific antigen levels. J. Aoac. Int. 89: $1121-1134$.

Messina, M. 2005. Soyfoods and soybean isoflavones for promoting bone health. Agro Food Ind. Hi-Tech. 16: 30-32.

Morris, P. F., M. E. Savard, and E. W. B. Ward. 1991. Identification and accumulation of isoflavonoids and isoflavone glucosides in soybean leaves and hypocotyls in resistance responses to Phytophthora megasperma f.sp. glycinea. Physiol. Mol. Plant P. 39(3): 229-244.

Murphy, S. E., E. A. Lee, L. Woodrow, P. Seguin, J. Kumar, I. Rajcan and G. R. Ablett. 2009. Genotype environment interaction and stability for isoflavones concentration in soybean. Crop Sci. 49: 1313-1321.

Njiti, V. K., D. A. Meksem, W. J. Banz and T. A. Winters. 1999. Molecular markers of phytoestrogen content in soybeans. J. Med. Food. 2: 165-167.

Primomo, V. S., V. Poysa, G. R. Ablett, C. J. Jackson, M. Gijzen and I. Rajcan. 2005. Mapping QTL for individual and total isoflavone content in soybean seeds. Crop Sci. 45: 2454-2464.

Pritchard, J. K., M. Stephens, N. A. Rosenberg and P. Donnelly. 2000. Association mapping in structured populations. Hum. Genet. 67: 170-181.

Barnes, S. 2010. The biochemistry, chemistry and physiology of the isoflavones in soybeans and their food products. Lymphatic Res. Biol. 8(1): 89-98.

Trigizano, R. N. and Caetano-Anolles, G. 1998. Laboratory exercises on DNA amplification fingerprinting for evaluating the molecular diversity of horticultural species. Horttechnology. 8: 413-423.

Tai, T. Y., K. S. Tsai, S. T. Tu, J. S. Wu, C. I. Chang, C. L. Chen, N. S. Shaw, H. Y. Peng, S. Y. Wang and C. H. Wu. 2012. Effect of soy isoflavones on bone mineral density in postmenopausal Taiwanese women with bone loss: A 2-year randomized double- 
blind placebo-controlled study. Osteoporos. Int. 23: 1571-1580.

Vyn, T. J., X. Yin, T. W. Bruulsema, C. C. Jackson, I. Rajcan and S. M. Brouder. 2002. Potassium fertilization effects on isoflavone concentrations in soybean (Glycine max (L.) Merr.). J. Agric. Food Chem. 50: 3501-3506.

Wang, Y., Y. Han, W. Teng, X. Zhao, Y. Li, L. Wu, D. Li and W. Li. 2014.
Expression quantitative trait loci infer the regulation of isoflavone accumulation in soybean (Glycine max L. Merr.) seed. BMC Genomics. 15: 680.

Zhang, J., C. Hao, Q. Ren, X. Chang, G. Liu and R. Jing. 2011. Association mapping of dynamic developmental plant height incommon wheat. Planta. 234: 891-902. 